\title{
Scaring off pirates
}

\section{Deep-sea drilling was the order of the day for Peter Clift and colleagues on their expedition to the South China Sea.}

\begin{abstract}
What was the objective of the work? The work built on several earlier projects which hinted that the evolution of the Asian monsoon and the Himalaya were closely linked. We had some clues that climate affects the location of faults in the modern mountains from earlier investigations of active tectonics, but it was not clear whether this relationship extended further back in time. Thus, we decided to reconstruct continental weathering in southern China and Tibet, the source region of the rivers that drain to the South China Sea, using sediment cores from the Pearl River system.
\end{abstract}

\section{Why did you choose this particular location for your work?}

We wanted to examine the effect of climate variability on the evolution of mountain belts, and the Himalaya (the largest mountain chain on Earth) seemed like the most obvious place to do this. Moreover, the Himalaya are associated with the Asian monsoon, one of the most dramatic climatic phenomena. If links between climate and tectonics couldn't be found there, it seemed unlikely they could be found anywhere else in the world.

\section{What sort of samples were you after?}

A remarkable record of continental weathering and erosion is preserved in offshore sedimentary basins around the world. Scientists (including our group) had already studied records from sedimentary basins in the Bay of Bengal and the Arabian Sea to understand rates of erosion in the eastern and western Himalaya. However, these records reflect both the

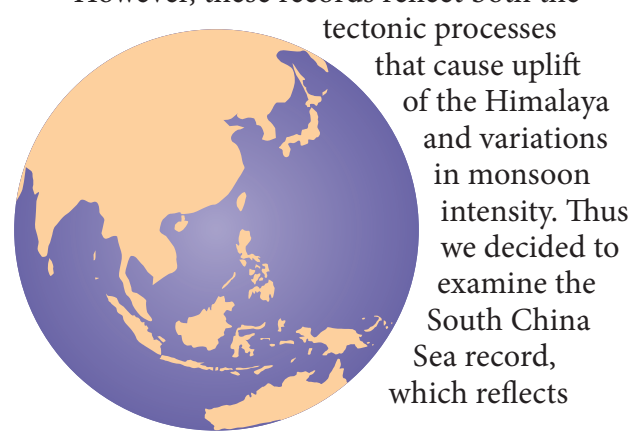

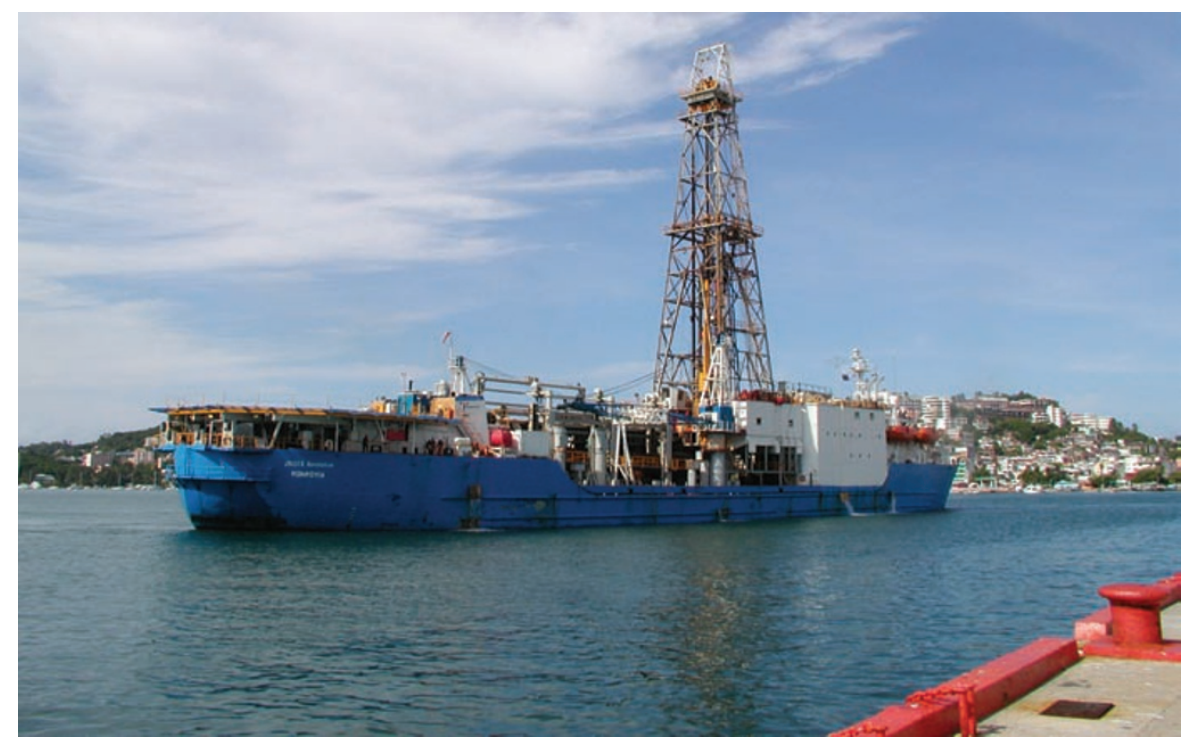

Deep-sea drilling ship used by Clift and colleagues.

climate-driven changes in weathering rate alone, allowing us to directly compare erosion records in the Himalaya with variations in climate. As usual, the field work was fun and the tedious part was done back at home - plotting and replotting numerous datasets and searching for correlations that might suggest causal relationships.

\section{Did you encounter any difficulties?} Drilling in the South China Sea was complicated by the threat of piracy and the competing territorial claims of various countries bordering the sea. When transiting the Sunda Strait, the captain made us go up on deck to ward off any pirates tempted to take us on: apparently they prefer lightly crewed ships with expensive cargoes, rather than 120-plus people on a deep-sea drilling mission.

\section{What was the highlight of the expedition?}

The first cold beer in Hong Kong after eight weeks of sampling on a dry drilling ship. The scientific high point came when my colleagues and I compared the South
China Sea data with records from the Arabian Sea and the Bay of Bengal, and saw remarkable correlations between the datasets, indicating co-variation in the South and East Asian monsoon systems. This made us feel sure that the climatic variations were widespread, and sent us looking for correlations with mountain evolution.

\section{Did the trip give you any ideas for future projects?}

The work shows very clearly that we need longer climate and weathering records for South and East Asia. At present, the model is heavily dependent on the South China Sea record; we really need to verify this using cores from South Asia. Frustratingly, the sediment records in the Himalaya show a large gap between $\sim 30$ and 20 million years ago. This means that we need to drill deep into the Arabian Sea and Bay of Bengal to recover long-duration weathering records for the region.

This is the backstory to the work by Peter D. Clift and colleagues, published on page 875 of this issue. 